\title{
Signos y palabras: la celebración del matrimonio tridentino en Lima y Charcas (s. XVI-XVIII) ${ }^{1}$
}

\author{
Pilar LATASA \\ Universidad de Navarra \\ platasa@unav.es
}

Recepción: 12 de febrero de 2016 / Revisión: 31 de marzo de 2016

Aceptación: 11 de mayo de 2016 / Publicación: Diciembre de 2016

\begin{abstract}
RESUMEN
La publicidad en la celebración del matrimonio fue uno de los aspectos esenciales abordados por los padres reunidos en el Concilio de Trento. A partir de ese momento se introdujeron antes, durante y después de la ceremonia nupcial una serie de condiciones que garantizaban esta publicidad, algunas de las cuales fueron, además, requerimientos para la validez del vínculo. Esta normativa tridentina se implementó pronto también en la América hispana. El trabajo aborda la aplicación del nuevo ritual matrimonial en los territorios de las archidiócesis de Lima y Charcas antes de la Pragmática Sanción de 1776. Con ese fin, se analizan tanto las disposiciones de concilios y sínodos locales, como los instrumentos de pastoral que más circularon en el ámbito andino.
\end{abstract}

Palabras clave: Concilio de Trento, matrimonio, celebración, ritual, amonestaciones, virreinato del Perú, Lima, Charcas, siglos XVI-XVIII.

\section{Signs and Words: the Celebration of Tridentine Matrimony in Lima and Charcas (16 $6^{\text {th }}-18^{\text {th }}$ Centuries)}

\begin{abstract}
Public disclosure of the celebration of matrimony was one of the essential issues addressed by the priests of the Council of Trent. From that point on, a series of conditions -to be met before, during and after the nuptial ceremony- were introduced in order to guarantee this disclosure; some were also required to validate the union. This Tridentine norm was soon to be implemented in Spanish America. This study addresses the application of the new matrimonial ritual within the territories of the Archdioceses of Lima and Charcas, before the Pragmatic Sanction of 1776. To this end, the provisions of local councils and synods are analyzed, as are the pastoral devices that were most common in the Andean sphere.
\end{abstract}

Keywords: Council of Trent, Matrimony, Celebration, Ritual, Admonitions, Viceroyalty of Peru, Lima, Charcas, $16^{\text {th }}-18^{\text {th }}$ Centuries.

Sumario: 1. Introducción. 2. Pasos previos: informaciones y amonestaciones. 3. La celebración del matrimonio. 4. Conclusiones y perspectivas. 5. Referencias bibliográficas.

1 Este trabajo está dentro de dos Proyectos I+D del Ministerio de Economía y Competitividad de España: Justicia eclesiástica y conformación de la sociedad en la América hispana, Ref. HAR2012-35197 y Discurso y poder, lengua y autoridad en el mundo hispánico (s. XVI-XVII), Ref. HAR2012-31536. Se elaboró en gran parte durante una estancia como investigadora invitada en el Max-Planck-Institut für europäische Rechtsgeschichte (2012); algunos de los materiales se recogieron en una estancia semejante en la John Carter Brown Library (2007). Agradezco estos apoyos que han posibilitado la investigación. 


\section{INTRODUCCIÓN}

El proceso de dar una forma canónica al matrimonio católico, que había sido durante siglos preocupación de Papas y Concilios, culminó en el Concilio de Trento². Gaudemet ha resumido la doctrina tridentina con respecto al matrimonio en cuatro puntos: carácter sacramental, indisolubilidad, papel de los padres y publicidad. Esta última quedó garantizada mediante los cambios introducidos en la celebración del sacramento ${ }^{3}$.

El decreto Tametsi estableció la forma definitiva: el matrimonio debía celebrarse ante la Iglesia (in facie ecclesiae) -lo cual suponía, en la práctica, la asistencia de un sacerdote-, delante de dos ó tres testigos y después de la publicación de amonestaciones durante tres misas mayores consecutivas ${ }^{4}$. Así, la historiografía ha destacado como, lo que antes habían sido solo recomendaciones, pasaron a ser requerimientos precisos que se introdujeron en la ceremonia nupcial para asegurar la validez del vínculo $^{5}$. Lombardi, por ejemplo, entiende que esta necesaria exteriorización del modo de contraer matrimonio tuvo dos consecuencias relevantes: la importancia del sacramento y su dimensión social resultaron reforzadas ${ }^{6}$.

Es precisamente esta dimensión social de la normativa tridentina -en un ámbito regional concreto y dentro de un contexto global- el marco en el que se sitúa este trabajo, en el que se trata de analizar la aplicación de esta nueva forma del matrimonio en el espacio colonial andino ${ }^{7}$. Como es sabido, los decretos tridentinos se implementaron pronto en la monarquía hispánica y, por supuesto, también en sus territorios indianos. A pesar de la existencia de estudios clásicos de gran valor sobre la aplicación de Trento en el Nuevo Mundo, y sobre el matrimonio en América, queda todavía mucho camino por recorrer en el conocimiento del tema a nivel local, sobre todo desde la perspectiva de la historia social ${ }^{8}$.

Lo interesante es que, aunque Trento estableció condiciones para que el matrimonio se celebrara válidamente, no precisó el ritual, dejando un amplio margen a la costumbre de cada lugar; incluso con la promulgación del Ritual Romano en 1614, los usos particulares siguieron vigentes:

si algunas provincias usan en este punto de otras costumbres y ceremonias loables, además de las dichas, desea ansiosamente el santo concilio que se conserven en un todo9?

La hipótesis de trabajo es que esta adaptación se llevó a cabo en la América hispana, y en concreto en las archidiócesis de Lima y Charcas, contando con dos variables: la costumbre matrimonial hispana y la idiosincrasia propia del territorio. Dentro de

2 ZARRI, 1996, pp. 437-483.

3 GaUdemet, 1993, pp. 323-326.

4 Morant Deusa - Bolufer Peruga, 1998, pp. 40-41; Usunáriz Garayoa, 2004, pp. 294-295.

5 Ibídem, pp. 257-267; ZARRI, 1996, pp. 437-438; LOMBARDI, 1996, pp. 215-222.

6 LOMBARDI, 2001, pp. 109-118.

7 Albani viene mostrando cómo la Congregación del Concilio, desde Roma, desempeñó un papel muy relevante en la aplicación local de Trento, también en América. Ver por ejemplo, ALBANI, 2009.

8 Villegas, 1975; RíPOdAS ARdanAZ, 1977.

9 Concilio de Trento en el Decreto de reforma sobre el matrimonio, cap. 1. 
esta última, ocuparía un lugar principal, como es lógico, la praxis matrimonial relativa a los indígenas; además habría que atender a modos de proceder propios, "indianos", que saldrían al paso de cuestiones planteadas en el Nuevo Mundo. Con este fin se han utilizado dos tipos de fuentes primarias.

El primer corpus está compuesto por los concilios y sínodos de las archidiócesis de Lima y Charcas hasta los llamados "concilios regalistas", que quedan fuera del análisis por estar ya vigente la Pragmática sobre matrimonio de 1776. Como es sabido, los decretos del Concilio de Trento se publicaron solemnemente en Lima el 28 de octubre de $1565^{10}$. Aunque el primer Concilio de Lima se había celebrado ya, se convocaron después cuatro concilios provinciales más en la Archidiócesis. Fueron el segundo (1567-1568) y, sobre todo, el tercer (1582-1583) limenses los concilios postridentinos más relevantes de Suramérica: ambos tuvieron un fuerte impacto en el territorio; en 1629 se celebró también el primer concilio de Charcas. Además, siguiendo las normas tridentinas y la práctica introducida por el arzobispo Toribio de Mogrovejo ${ }^{11}$, se reunieron en ambas archidiócesis un elevado número de sínodos en el periodo estudiado, a diferencia de lo que ocurrió en la Nueva España. En la medida que Trento dio a estas asambleas capacidad para el gobierno de las diócesis, los obispos de la América del Sur hispana las aprovecharon para implantar la reforma católica a nivel local, aplicando el derecho canónico a la peculiar situación de cada diócesis ${ }^{12}$.

El segundo corpus de fuentes primarias utilizado está formado por tratados que desarrollaban la doctrina de Trento adecuándola a la singularidad del Nuevo Mundo. La relación entre los concilios y sínodos y estas obras fue muy estrecha: los primeros recomendaron su manejo y en algunos casos promovieron su elaboración. Estos instrumentos de pastoral o manuales para párrocos, de tipología variada -catecismos, rituales, confesionarios y libros de sermones, principalmente- se convirtieron así también en herramientas esenciales para la difusión de estas nuevas pautas matrimoniales ${ }^{13}$.

En América circularon los manuales sacramentales diocesanos más difundidos en la península ibérica: el Manual Hispalense de la segunda mitad del siglo XIV y, sobre todo, el Toledano, aparecido en el siglo XIII, que fue reeditado varias veces hasta que en 1583 apareció adaptado a la normativa tridentina: fue precisamente en ese momento cuando comenzó a usarse de forma general en la península y en los territorios indianos. El Toledado postridentino era mucho más rico en ritos, contenido y expresividad que el Ritual Romano, que aparecería en 1614 con una clara aspiración uniformadora, compatible de nuevo con el mantenimiento a nivel local de costumbres y ceremonias propias de los distintos pueblos del orbe católico ${ }^{14}$.

10 TINEO, 1990, pp. 151-155.

11 Convocó trece sínodos en la diócesis de Lima. AranciBia - DellafErrera, 1978, p. 18.

12 Lombardi, 1996, p. 225, incide en la trascendencia de los sínodos italianos para la puesta en práctica de Trento. Para Indias lo destacaron, entre otros, AzNAR GiL, 1985, pp. 10-15; Roca SuÁreZ-Inclán, 1995, pp. 46 y 60-62.

13 Sobre estos manuales y algunos de los autores que se abordan en este trabajo ver: SARANYANA - ALEJOS GraU, 1996, pp. 107-184.

14 Aznar Gil, 1992, p. 213; García Alonso, 1958, pp. 351-450 y 1959, pp. 323-399; Borobio García, 1993, pp. 70-73. 
Estos textos hispanos fueron fácilmente trasladables al grupo español del Nuevo Mundo. Sin embargo, entre los evangelizadores surgió pronto la necesidad de contar con obras más breves para los indígenas, adaptadas a ellos e incluso traducidas a sus lenguas. Entre esos textos destacó el llamado Manual Mexicano Pequeño ${ }^{15}$-elaborado a partir del nuevo Misal Romano- en el que se simplificaban y abreviaban las principales ceremonias. Este manual se difundió por todo el territorio indiano y fue también preferido por los españoles ${ }^{16}$.

Para el ámbito andino, a partir de las fuentes mencionadas y de otros rituales hispanos y europeos, el franciscano Luis Jerónimo de Oré redactó un importante Ritual Peruano políglota en castellano, quechua, aymara, puquina y guaraní que fue impreso en Nápoles en 1607 y aspiró a ser un ritual válido para todo el territorio del virreinato ${ }^{17}$.

Tras la publicación en 1614 del Ritual Romano, que llevaba anejo el Toledano, Juan Pérez Bocanegra, cura párroco de la doctrina de Andahuaylillas, elaboró una versión del mismo en castellano y quechua, publicada en Lima en 1631. Aunque en realidad se trató de una obra más completa, un manual de párrocos titulado: Ritual formulario e instrucción de curas, que manifestaba un profundo conocimiento del ámbito rural andino ${ }^{18}$, en ella se actualizaba la celebración del matrimonio, con especial atención a los indígenas:

Me parece se guarde al pie de la letra lo que este santo Ritual manda en estas partes e Indias occidentales y en todas el mundo, aunque hasta ahora se hayan guardado las ceremonias de los antiguos manuales en la administración del santo sacramento del matrimonio (...) advirtiendo cada cura a sus feligreses por sí y, si no, (...) por algún intérprete lo que se ha quitado de lo antiguo y mandado de lo nuevo en este Ritual moderno, con facilidad lo asentirán y guardarán ${ }^{19}$.

Otro texto esencial para el ámbito de estudio es el Itinerario para párrocos de indios del obispo de Quito, Alonso de la Peña Montenegro, publicado en 1668, que se convirtió en un texto de referencia para los doctrineros andinos ${ }^{20}$. De Quito era oriundo Juan Machado de Chaves, clérigo criollo que publicó en Barcelona, en 1641, su Perfecto confesor y cura de almas, obra que no llegó a tener la difusión de la anterior pero es un significativo ejemplo del género de los confesonarios indianos. Ha sido también de utilidad la consulta del tratado de moral Flores summarum, del ilustre jesuita limeño Juan de Alloza, impreso en Lieja en $1665^{21}$. La lista podría continuar, se han indicado solo aquellos instrumentos que tuvieron un marcado carácter andino por haber sido elaborados a partir de la experiencia pastoral de sus autores o de personas

\footnotetext{
15 A partir de uno mandado elaborar por Montúfar y publicado en 1568, el franciscano Miguel de Zárate redactó su propio ritual que contó con sucesivas reimpresiones: ZÁrate, 1734. Este último es el Manual Mexicano pequeño según Lundberg, 2011, pp. 121-125. Ver también ZulaiCa Gárate, 1991, pp. 193-194.

16 Así lo confirma Peña Montenegro, 1995, vol. II, pp. 29-30.

17 ORÉ, 1607.

18 Mannheim, 2012.

19 PÉrez Bocanegra, 1631, pp. 585-587.

20 Rimbau MuÑoz, 1988 aborda la cuestión del matrimonio en este autor.

21 Sobre este jesuita véase CoEllo DE LA RosA, 2005.
} 
cercanas a ellos. Sin embargo, en el trabajo se han cotejado otros que procedentes de la Nueva España que circularon igualmente por el virreinato del Perú.

A través de estos textos y de las disposiciones de concilios y sínodos andinos se pretende rastrear el ritual del matrimonio utilizado en las extensas regiones que dependían de las dos archidiócesis del virreinato: Lima y La Plata ${ }^{22}$. Este análisis se realiza prestando especial atención a los cuatro momentos en que la forma tridentina de celebración establecía la necesaria presencia del párroco con el fin de reforzar el nuevo carácter público del matrimonio ${ }^{23}$ : las amonestaciones, los desposorios, las velaciones o bendiciones nupciales y el registro parroquial ${ }^{24}$.

\section{PASOS PREVIOS: INFORMACIONES Y AMONESTACIONES}

El párroco, en efecto, desempeñaba un papel esencial en la etapa previa a la celebración del matrimonio ${ }^{25}$. Era el responsable de garantizar que los contrayentes cumplían las condiciones necesarias para casarse. Alonso de Molina detallaba en su Confesionario mayor en la lengua mexicana y castellana (1569), cómo se debía averiguar si los novios estaban bautizados y conocían la doctrina sobre el sacramento del matrimonio, si eran esclavos o libres, si eran solteros, si eran naturales del lugar donde querían casarse o no, si tenían la edad necesaria para contraer matrimonio-14 años el hombre y 12 la mujer-, si existía entre ellos algún impedimento de parentesco, si alguno de ellos había dado ya promesa de matrimonio a otra persona y si acudían libremente a contraer matrimonio ${ }^{26}$. Así, cuando una pareja se presentaba ante el párroco para recibir este sacramento, se iniciaba una investigación que culminaba en la elaboración por parte del cura de las llamadas "informaciones" previas al matrimonio, en las que se abordaban los puntos indicados. No fue esta una práctica propia del Nuevo Mundo, ni una novedad tridentina. Sin embargo, la insistencia en la publicidad por parte del Concilio, sin duda asentó en la América hispana estas averiguaciones preliminares, sobre las que se legisló de forma reiterada en los sínodos y concilios andinos de los siglos XVI al XVIII ${ }^{27}$.

También era competencia del párroco implicar a otras personas en esta etapa preliminar mediante la publicación de las amonestaciones. Ya desde el siglo XII las Decretales de Alejandro III habían establecido la necesidad de publicitar de esta forma el matrimonio. La exigencia de moniciones fue adoptada un siglo más tarde por el concilio de Letrán (1215) y reiterada a partir de ahí en asambleas eclesiásticas pos-

22 El tema se abordó ya para el siglo XVI y primeras décadas del XVII en LATASA, 2005.

23 Al mismo tiempo Trento recordó que la causa efficiens era el consentimiento mutuo de los esposos. Ver: SсHӧсH, 1997, pp. 639-672.

24 Recoge las etapas del matrimonio en la Italia del XVI: LombARDI, 2001, pp. 228-230, 240.

25 ZARRI, 1996, pp. 457-459, destaca que el nuevo protagonismo dado al párroco se debió a razones pastorales y al interés por reforzar la presencia de la Iglesia en la formación del matrimonio.

26 Molina, 1984; Palafox y Mendoza, 1864, p. 128. Lo recoge Lombardi, 2001, pp. 114-118, 235.

27 Por ejemplo, en el Sínodo de Arequipa, 1638, lib. 2, tit. 8, cap. 2. Constituciones sinodales del Obispado de Arequipa en el sínodo que se celebró en dicha Diócesis el año de 1638 hechas y ordenadas por don Pedro de Villagómez, Obispo de Arequipa. Manuscrito en la Biblioteca Nacional de España (en adelante BNE). 
teriores ${ }^{28}$. Aznar Gil ha estudiado cómo, a partir del cuarto lateranense, los concilios y sínodos ibéricos bajomedievales -al igual que ocurrió en Francia, Inglaterra y otros lugares de Europa- aplicaron, desarrollaron y ampliaron la normativa sobre las proclamas que debían preceder a la celebración del matrimonio, e incluso salieron al paso de cuestiones que no habían sido previstas por este Concilio ${ }^{29}$. Finalmente, el decreto Tametsi del Concilio de Trento dispuso de forma precisa que se hicieran tres veces, en días de fiesta seguidos, en la iglesia y durante la misa mayor ${ }^{30}$. Se trataba con ello, tanto de frenar los matrimonios clandestinos, como de garantizar la capacidad de los novios para contraer matrimonio, permitiendo que los miembros de la comunidad manifestasen los posibles impedimentos.

La lectura de proclamas fue ya recogida por los concilios y sínodos indianos anteriores a Trento por influencia del Concilio hispalense de $1512^{31}$. Para el ámbito del virreinato peruano se reiteraron con nuevo vigor en los concilios limenses postriden$\operatorname{tinos}^{32}$. Una muestra de ello fue la publicación, entre los complementos pastorales del Confesionario para curas de indios del tercer limense, de una Forma común de hacer las amonestaciones, impresa en Lima en $1585^{33}$.

Los sínodos andinos posteriores se hicieron también eco de la importancia de las amonestaciones. Así, por ejemplo, el de Lima de 1613, que reunió y actualizó los cánones de los sínodos diocesanos anteriores, recordó la necesidad de publicitar el matrimonio y estableció penas para aquellos sacerdotes que omitieran este paso; aunque las amonestaciones no eran esenciales para el matrimonio, los padres sinodales recordaron que pecaban mortalmente el párroco y los contrayentes que las omitían ${ }^{34}$.

La publicación del mencionado Ritual romano de 1614 supuso un paso adelante en la regulación definitiva de las proclamas: además de incluir un texto normalizado para realizarlas, se estableció de forma precisa que los futuros esposos debían ser amonestados por su propio párroco, en tres días de fiesta continuos, en lengua vulgar y en la iglesia durante la celebración de la misa mayor; además, si procedían de distintas parroquias se debían publicar en ambas. Estas exigencias fueron, de hecho, incorporadas por sínodos andinos posteriores como los de Arequipa y La Paz de 1638 y el de La Paz de 1738; también en manuales para párrocos como el de Pérez Bocanegra (1631) y el tratado Flores summarum de Juan de Alloza (1665) ${ }^{35}$.

Al igual que en la Península, los sínodos andinos prestaron especial atención a los tiempos y el lugar en que se debían hacer las proclamas. Así, por ejemplo, el de

\footnotetext{
28 GAUdEMET, 1993, p. 266.

29 AzNAR Gil, 1999, pp. 139-153, 159.

30 Concilio de Trento, ses. 24, De refomatione circa matrimonium, cap. 1. AzNAR GIL, 1992, p. 205; GAUDEMET, 1993, pp. 329-330.

31 AzNAR Gil, 1992, p. 203; RÍPODAs Ardanaz, 1977, p. 75.

32 Concilio de Trento, ses. 24, De refomatione circa matrimonium, cap. 1. Primer concilio de Lima, 15511552, pte. 1, cons. 24 y pte. 2, cons. 63; Segundo concilio de Lima, 1567-1568, pte. 1, caps. 15, 18, 21 y pte. 2 , caps. 64, 65, 70; Tercer concilio de Lima, 1582-1583, act. 2, cap. 34. VARGAS UGarte, 1951.

33 DurÁN, 1982, p. 492.

34 Sínodo de Lima, 1613, lib. 4, tit. 1, cap. 3. Soto Rábanos, 1987.

35 Rituale Romanum Pauli V, fs. 304-305; PÉRez Bocanegra, 1631, pp. 497-498; Sínodo de La Paz, 1638, lib. 4, tit. 1, cap. 1. Constituciones, 1970b; Sínodo de Arequipa, 1638, lib. 2, tit. 8, cap. 1. Constituciones sinodales del Obispado de Arequipa, BNE; Sínodo de La Paz, 1738, cap.3, ses.7, cons. 4 y 12. ConstituCIONES, 1970c, este Sínodo ha sido estudiado por BARNADAS, 1967.
} 
Arequipa de 1638 recordó que no se debían publicar amonestaciones en la misa de los sábados no festivos -aunque por devoción mariana acudieran muchos fieles- porque la asistencia era siempre menor que los domingos ${ }^{36}$. Especialmente precisa en cuestión de amonestaciones fue la asamblea reunida en la misma ciudad en 1684, en la que se concretó que entre la primera amonestación y la última debían pasar al menos ocho días: se trataba con ello de evitar que se hicieran en tres días de fiesta sucesivos, circunstancia que podía dificultar que la noticia llegase a todos los parroquianos. Así mismo, el Sínodo de La Paz de 1738, limitó las amonestaciones en tres días festivos continuos -como ocurría en Pascua- a personas "que por su notoria honra y cristiandad no dejen prudente recelo de que entre ellas pueda haber impedimento alguno" y recomendó, en cambio, que habitualmente se respetara el margen de los ocho días entre la primera y la tercera amonestación; también dispuso que después de la última se dejaran pasar al menos veinticuatro horas para celebrar el matrimonio -plazo que ya había propuesto un siglo antes Pérez de Bocanegra en su manual- ${ }^{37}$, y censuró que algunos curas publicaran las amonestaciones fuera de la iglesia parroquial, en otras misas y vísperas, sin esperar a los días de fiesta ${ }^{38}$.

Los tiempos de las proclamas se ralentizaban necesariamente cuando los contrayentes eran de distinta procedencia y debían publicarse en ambas parroquias: así se recogía en el Sínodo de Arequipa de $1684^{39}$ y en otras asambleas posteriores, como el Sínodo de Córdoba de 1700, el de La Paz de 1738 y el de Santiago de Chile de 1763, que incidieron en este punto ${ }^{40}$.

Finalmente, siguiendo de nuevo lo dispuesto por el Ritual romano de 1614, tanto el manual de Pérez Bocanegra como el sínodo de Arequipa de 1684, incorporaron una caducidad de dos meses para las amonestaciones de modo que, si el matrimonio se celebraba finalmente más tarde, era preciso publicar nuevas moniciones ${ }^{41}$.

Otro aspecto de la regulación sinodal en materia de amonestaciones fue el diferente trato dado a los indígenas. En un primer momento, debido a las dificultades para introducir el matrimonio cristiano entre la población nativa, se dispuso que -además de las establecidas- se realizaran unas «amonestaciones» especiales en las que se preguntara directamente a los naturales, empezando por los curacas, acerca de la existencia de posibles impedimentos. Así se reguló ya en el segundo concilio provincial de Lima, en el Sínodo de Quito de 1570, en el de Lima de 1585 y en el de Tucumán

\footnotetext{
36 Sínodo de Arequipa, 1638, lib. 2, tit. 8, cap. 3. Constituciones sinodales del obispado de Arequipa, BNE.

37 Sínodo de La Paz, 1738, cap. 3, ses. 7, const. 10. Constituciones, 1970c; Pérez Bocanegra, 1631, pp. $592-599$ y $624-630$.

38 Sínodo de La Paz, 1738, cap. 3, ses. 7, const. 21. Constituciones, 1970c.

39 Sínodo de Arequipa, 1684, lib. 1, tit. 10, cap. 6. Constituciones, 1971; Sínodo de Córdoba, 1700, cap. 3, tit. 5, lib. 2. Dellaferrera - Martini, 2002; Sínodo de La Paz 1738, cap. 3, ses. 7, cons. 11. ConstitucioNES, 1970c; Sínodo de Santiago de Chile, 1763, tit. 8, cons. 7 y 11. SínOdos, 1983.

40 RíPodas Ardanaz, 1977, pp. 75-76, ya mencionó esta tendencia a no acelerar el ritmo de las proclamas.

41 Rituale Romanum Pauli V, p. 305; Pérez Bocanegra, 1631, p. 586; Sínodo de Arequipa, 1684, tit. 10, caps. 3 y 7. ConstituCiones, 1971. La norma del Ritual romano se generalizó, como lo prueba el que este mismo plazo fuera recogido por el sínodo de Florencia de 1619: ver LOMBARDI, 2001, pp. 235-236.
} 
de 1597 , que establecieron además penas para quienes ocultaran la existencia de vínculos de parentesco entre los novios ${ }^{42}$.

También exclusiva de los indígenas fue la actuación inicial de simplificar el trámite de las proclamas con el fin de evitar que la formación del matrimonio se dilatara en el tiempo ${ }^{43}$, ya en el decreto Tametsi del Concilio de Trento se preveía la posibilidad de reducir el número de amonestaciones si estas dificultaban el matrimonio ${ }^{44}$. El análisis de las sinodales peruanas permite afirmar que la Iglesia optó en estos casos, no tanto por la reducción del número como por la simplificación de la solemnidad. Por ejemplo, los sínodos de Cuzco de 1591, de Quito de 1594 y de Arequipa de 1638 permitieron que las proclamas para matrimonios entre indígenas se hicieran, una en día de fiesta y las dos restantes cuando estuvieran reunidos para la catequesis, por considerarse que había entonces "concurso del pueblo", según exigía Trento. Autores como Alloza y Pérez Bocanegra se sumaron también a esta opción ${ }^{45}$. No obstante, hubo otra corriente favorable a no hacer este tipo de distinciones: así, tanto el sínodo de Trujillo de 1624 como el Arequipa de 1684, aconsejaron que las amonestaciones se hicieran también en días feriados en las doctrinas de indios ${ }^{46}$. La ausencia de disposiciones específicas en este sentido en los sínodos andinos posteriores induce a pensar que prevaleció esta segunda tendencia y la publicación en días feriados acabó siendo la práctica general ${ }^{47}$.

A pesar de que uno de los objetivos de las amonestaciones era confirmar la libre voluntad de los contrayentes, los sínodos salieron al paso de algunos abusos por los que la publicación de proclamas se convertía en un modo de coacción para uno o ambos cónyuges. Así, el Sínodo de Lima de 1613 prohibió que se situara a los futuros contrayentes indígenas en las gradas de altar para amonestarlos, "por los inconvenientes que ha habido y que algunos se retraen por no pasar esta vergüenza"48. Pero lo más reiterado fue, sin duda, la prohibición de publicar las amonestaciones a instancias de una sola parte. Se trataba de evitar que, al dar publicidad a la futura boda, alguno se viera obligado a casarse. Sucesivos sínodos andinos de los siglos XVII y

42 Segundo concilio de Lima, 1566-1567, pte. 2, const. 65-66 en VArgas UGARTe, 1951; Sínodo de Quito I, 1570, pte. IV, cons. 43. Mateos, 1968; Sínodo de Lima, 1585, caps. 28 y 85. Compendio, 1606; Sínodo de Tucumán, 1597, pte. 2, cons. 4 y 5. Arancibia - Dellaferrera, 1978; AzNAR Gil, 1992, pp. 205-206.

43 Incluso se permitió que, si el cura temía que convivieran antes de casarse y le constaba que no había impedimentos, se suprimieran las amonestaciones: Sínodo de Tucumán, 1597, pte. II, cons. 5 en ArANCIBIA Dellaferrera, 1978; Rípodas ArdanAZ, 1977, pp. 75-76.

44 Lo incorporaba ya el Segundo Concilio de Lima, 1567-1568, pte. 2, caps. 65 y 66. VARGas UGarTe, 1951.

45 Sínodo de Quito, 1594, cap. 17. Constituciones, 1981; Sínodo de Cuzco, 1591, cap. 22. LASSÈGEMorèles, 1987; Sínodo de Arequipa, 1638, lib. 2, tit. 8, cap. 3. Constituciones sinodales del obispado de Arequipa, BNE; AllozA, 1665, pp. 497-498; PÉREZ BoCANEGRA, 1631 pp. 592-599 y 624-630.

46 Constituciones sinodales del Obispado de Trujillo del Perú hechas y ordenadas por el Reverendísimo S. Don Carlos Marcelo Corne, obispo de la dicha ciudad de Trujillo, del Consejo de Su Majestad y publicadas en la sínodo diocesana que su señoría reverendísima celebró en la dicha ciudad el año del Señor de 1623. Manuscrito en Archivo General de Indias (en adelante AGI), Lima, 307, act. 4, cap. 2; Sínodo de Arequipa, 1684, lib. 1, tit. 10, cap. 5. Constituciones, 1971.

47 El obispo de Puebla, Palafox y Mendoza, recomendaba observar en materia de amonestaciones lo mismo que con los españoles en su manual, publicado por primera vez 1642. PALAFOx y MeNDOZA, 1864, pp. 134-135.

48 Sínodo de Lima, 1613, lib. 4, tit. 1, cap. 3. Soto Rábanos, 1987; Aznar Gil, 1992, p. 207. 
XVIII dispusieron, del mismo modo, que el párroco debía tener constancia previa, por escrito e incluso ante notario público en el caso de ausentes, de la libre voluntad de ambos para casarse, de modo especial de la mujer, que era la que habitualmente podía verse coaccionada ${ }^{49}$.

Fue también preocupación de las asambleas eclesiásticas evitar que se dispensara de las amonestaciones sin motivos suficientes, en contra de lo dispuesto por Trento. La normativa sobre dispensas fue recogida para el Perú por el tercer limense y de ahí paso a las sinodales andinas; a mediados del siglo XVII Juan de Alloza sistematizó las causas ${ }^{50}$. Sin embargo, ya a comienzos del siglo XVII el sínodo de Cuzco de 1601 condenó la práctica introducida entre visitadores, vicarios y curas de dispensar de amonestaciones y recordó que estas dispensas eran competencia del obispo o su provisor $^{51}$. Los Sínodos andinos posteriores insistieron también en que estas dispensas correspondían únicamente al ordinario, que podía aplicarlas cuando había motivos suficientes ${ }^{52}$. Pero el abuso de dispensas no fue algo propio del mundo andino, de hecho el Ritual Romano de 1614 estableció que si el párroco tenía razones para pensar que había quienes tratarían de impedir el matrimonio al publicarse las amonestaciones, podía reducirlas a una e incluso omitirlas, celebrar el matrimonio y publicar después las amonestaciones pendientes, antes de que se hubiese consumado ${ }^{53}$ : así, se procuraba impedir posibles presiones, casi siempre familiares, sin suprimir las amonestaciones. Autores como Mentrida, Pérez Bocanegra y Alloza se hicieron eco de esta solución en sus manuales ${ }^{54}$.

Sin embargo, la reiteración de la normativa sobre dispensas de amonestaciones en el XVIII confirma la facilidad con que generalmente se despacharon. Por ejemplo, los padres sinodales reunidos en La Paz en 1738 denunciaron el abuso de conceder

49 Sínodo de Trujillo, 1624, act. 4, cap. 2. Constituciones sinodales del obispado de Trujillo del Perú (...), AGI, Lima, 307; Sínodo de Arequipa, lib. 2, 1638, tit. 8, cap. 1. Constituciones sinodales del obispado de Arequipa, BNE; Sínodo de Arequipa, 1684, lib. 1, tit. 10, cap. 4. Constituciones, 1971; Sínodo de La Paz, 1738, cap.3, ses. 7, cons. 20. Constituciones, 1970c; Aznar GiL, 1992, p. 207. También Pérez Bocanegra, 1631, p. 586.

50 Rí́podas Ardanaz, 1977, pp. 79-81; Tineo, 1990, p. 424; Tercer concilio de Lima, 1582-1583, act. 2, cap. 34. Vargas Ugarte, 1951; Alloza, 1665, pp. 498-499. Sobre la concesión de estas dispensas ver: LATASA, 2008, pp. 53-67.

51 Sínodo de Cuzco, 1601, cap. 21. Analectes, 1831.

52 Sínodo de Trujillo, 1624, act. 4, cap. 2. Constituciones sinodales del Obispado de Trujillo del Perú (...), AGI, Lima, 307; Sínodo de La Plata, 1628, De officio vicarii. Constituciones sinodales del Arzobispado de la ciudad de La Plata, provincia de Los Charcas, en el Perú. Hechas y ordenadas por el ilustrísimo y reverendísimo señor doctor don Fernando Arias de Ugarte, arzobispo de la dicha ciudad, del Consejo de Su Majestad, y publicadas en la sínodo diocesana que su señoría ilustrísima celebró en la dicha ciudad de La Plata en cuatro días del mes de mayo de 1628. En los Reyes. Impreso por Gerónimo de Contreras, 1629; Sínodo de Lima, 1636, cap. 2. Sото Rábanos, 1987, pp. 27-28; Sínodo de Arequipa, 1638, lib. 2, tit. 8, cap. 3. Constituciones sinodales del obispado de Arequipa, BNE; Sínodo de Arequipa, 1684, tit. 10, cap. 5. ConsTITUCIONES, 1971; Sínodo de Santiago de Chile, 1688, cap. 4, cons. 10. Sínodos, 1983; Sínodo de La Concepción, 1744, cap. 5, cons. 10 y 26. Sínodo, 1984; Sínodo de Santiago de Chile, 1763, tit. 8, cons. 15. Sínodos, 1983. De forma semejante se legisló en las asambleas rioplateneses: en el Sínodo de Tucumán en 1597, el de Asunción en 1603, el de La Plata en 1619-1620 y el de La Paz en 1638. Dellaferrera - Martini, 2002, p. 128; Barnadas, 2002; CONSTituCiOnes, $1970 \mathrm{~b}$.

53 Desde Alejandro III estaba vigente la doctrina según la cual el matrimonio consumado era indisoluble.

54 Rituale Romanum Pauli V, p. 305. Mentrida, 1630, pp. 81-82; Pérez Bocanegra, 1631, p. 586; Alloza, 1665, pp. 497-498. 
la dispensa de proclamas sin más motivo que la voluntad de los contrayentes, hasta el punto que parecía socialmente menos importante una boda sin dispensas, con los problemas que esto podía generar en cuanto al desconocimiento de impedimentos ${ }^{55}$.

Del mismo modo, el Sínodo de La Concepción de 1744 lamentaba la costumbre introducida entre la "gente principal" de casarse sin amonestaciones y, en general, la facilidad con que se daban dichas dispensas. Es elocuente, en este sentido, que la misma asamblea recordaba la restricción de no festejar las bodas para las que se había dado dispensa de amonestaciones con fiestas, bailes y músicas que ocasionaban la publicidad que se había querido evitar ${ }^{56}$.

La regulación tridentina con referencia a los pasos previos al matrimonio tuvo, por lo tanto, un amplio eco, tanto en concilios y Sínodos andinos como en instrumentos de pastoral locales. De estas fuentes emerge una casuística, por un lado similar a la planteada en otros lugares y por otro peculiar, sobre todo en lo referente las amonestaciones en matrimonios entre indígenas, aunque con el tiempo se tendió a dar pautas comunes para toda la población.

\section{LA CELEBRACIÓN DEL MATRIMONIO}

Desde la Baja Edad Media la celebración del matrimonio cristiano constaba de dos partes claramente diferenciadas ${ }^{57}$. La primera era propiamente el desposorio o la celebración del matrimonio mediante el intercambio del consentimiento por palabras de presente entre los contrayentes. La segunda era la ceremonia litúrgica de las velaciones o bendiciones nupciales, que tenían lugar durante la misa.

Trento recogió estos dos momentos y estableció que el primero, el intercambio del consentimiento matrimonial, fuera emitido por los contrayentes "in facie ecclesiae" por "palabras de presente" -en presencia del párroco propio y de dos o tres testigos-. Según han destacado Cristellon y Seidel, el concilio supuso un punto de inflexión en la celebración del sacramento: con estos requisitos consiguió desplazar las bodas al espacio público, quitar a los novios y la familia el control sobre la ceremonia y propiciar una liturgia uniformada que se difundió con el Ritual Romano de $1614^{58}$.

\subsection{La presencia del párroco}

Lombardi ha señalado como el párroco pasó a ser una figura central en las etapas que constituían la formación del matrimonio ${ }^{59}$. Debía estar presente en calidad de testigo en el intercambio de los consentimientos para asegurar su publicidad y, finalmente,

\footnotetext{
55 Sínodo de La Paz, 1738, cap. 3, ses. 7, const. 11. Constituciones, 1970c.

56 Sínodo de La Concepción, 1744, cap. 15, cons. 5. SínOdo, 1984.

57 Donahue, 2007, pp. 16-18.

58 GAUDEMET, 1993, pp. 330-333.

59 LOMBARDI, 2001, pp. 114-118.
} 
impartir las bendiciones nupciales. Este protagonismo fue asumido gradualmente y reforzado por el Ritual Romano de Paulo V de $1614^{60}$.

Como no podría ser de otra forma, la insistencia en este punto fue una constante en los concilios y sínodos andinos. Sus constituciones recordaron que, según lo dispuesto por Trento, solo podía intervenir un cura ajeno si contaba con licencia expresa del cura propio o del ordinario ${ }^{61}$; esta prohibición incluía también a visitadores y vicarios $^{62}$. A tenor de esta normativa, Juan Pérez Bocanegra, en su Ritual formulario (1631) asumió la necesaria presencia del propio párroco en la celebración del matrimonio; en términos parecidos la incorporó también el jesuita Juan de Alloza en su Flores summarum $(1655)^{63}$.

En Indias estas disposiciones deben entenderse también a la luz de la experiencia pastoral que confirmaba la frecuencia con la que los indígenas que tenían algún impedimento para contraer matrimonio se trasladaban a otras parroquias para lograrlo ${ }^{64}$. De ahí que fuera también muy reiterada la prohibición de casar a personas «vagantes» sin hacer antes averiguaciones en sus lugares de origen ${ }^{65}$.

\subsection{Los testigos necesarios}

La publicidad del matrimonio venía dada también por la presencia de dos o tres testigos en el intercambio del consentimiento. Los concilios y sínodos andinos de los siglos XVI y XVII se limitaron, en general, a reiterar lo dispuesto por Trento ${ }^{66}$.

Sin embargo, Juan Machado de Chaves, en su Perfecto confesor (1641), dejó notables consideraciones en el asunto. Explicaba que Trento había introducido la necesidad de testigos en la celebración del matrimonio para evitar "los engaños y maldades que antiguamente se cometían cuando los matrimonios se celebraban con solo el consentimiento de las partes". Así, remarcaba que los testigos debían estar presentes en el intercambio de consentimientos de forma activa, entendiendo y advirtiendo lo que se hacía, de modo que -si fuera necesario- pudieran luego declarar sobre lo acontecido. En ese sentido, se preguntaba si podían actuar como testigos personas que habían

60 CRISTEllon, 2009, pp. 10-30 muestra cómo la determinación sobre quién era realmente el propio párroco suscitó en Italia numerosos debates y exigió la intervención de la Congregación del Concilio.

61 Sínodo de Cuzco, 1591, cons. 41. LassèGe-Morèles, 1987; Sínodo de Lima, 1594, cons. 29; Sínodo de Quito, 1594, cap. 19. Constituciones, 1981; Sínodo de Lima, 1596, cons. 99; Sínodo de Lima, 1600, cons. 12; Sínodo de Lima, 1604, cons. 34; Sínodo de Trujillo, 1624, act. 4, cap. 2. Constituciones sinodales del Obispado de Trujillo del Perú (...), AGI, Lima, 307; Sínodo de Arequipa, 1638, tit. 1, cap. 3. Constituciones sinodales del Obispado de Arequipa, BNE; Sínodo de Lima, 1636, cap. 9. Soto RÁbanos, 1987, pp. 25-26; Sínodo de Arequipa, 1684, lib. 1, tit. 10, caps. 1 y 2. Constituciones, 1971. Los sínodos de Lima citados están en COMPENDIO, 1606.

62 Sínodo de Lima, 1600, cons. 2. Compendio, 1606; Sínodo de La Plata, 1628, De officio vicarii en Constituciones sinodales del Arzobispado de la ciudad de La Plata, 1628. En los Reyes. Impreso por Gerónimo de Contreras, 1629.

63 Pérez Bocanegra, 1631, pp. 584-585; Alloza, 1665, pp. 496-501.

64 Concilio de La Plata, 1629, p. 103. Velasco, 1964; Palafox y Mendoza, 1864, pp. 133, 154-155, recomendaba por este motivo especial prudencia al casar a indígenas de otra feligresía.

65 Sínodo de Arequipa, 1638, lib. 2, tit. 8, cap. 1 y tit. 10, cap. 5. Constituciones sinodales del obispado de Arequipa, BNE. Fue esta una problemática típicamente andina como se puede ver en ZABALLA BEASCOECHEA, 2016, pp. 73-79.

66 Concilio de Trento, ses. 24, De refomatione circa matrimonium, cap. 1. 
sido forzadas o engañadas para estar presentes en la celebración y concluía de forma afirmativa. Finalmente, se planteaba si los testigos debían ser personas "mayores, de toda excepción", es decir, las más acreditadas, y se inclinaba por la opinión predominante que únicamente exigía a los testigos tener uso de razón ${ }^{67}$.

Años más tarde Alonso de Peña Montenegro incluiría algunas consideraciones sobre los testigos en su Itinerario para párrocos de indios, publicado en 1668, en el que recordó que, desde Trento, la presencia del párroco y testigos era intrínseca y necesaria a la materia y forma del sacramento, que era el consentimiento mutuo. Los testigos, que asistían al matrimonio, debían tener uso de razón y entender cómo se otorgaban en marido y mujer: no eran por tanto válidos niños ni personas ebrias. Peña Montenegro se mostraba en cambio más flexible en lo referente a no entender los testigos la lengua de los contrayentes, en estos casos se podía usar intérpretes e incluso era posible deducir el consentimiento por alguna señal ${ }^{68}$.

El sínodo de La Paz de 1738 dedicó al tema una constitución en la que incidió en la necesidad de contar con testigos «ciertos y determinados» de los que debía constar nombre propio y domicilio. Precisaba, por ejemplo, que no era válido entender que había estado presente toda la vecindad: debían ser personas concretas que hubieran oído y entendido la aceptación de los consentimientos; tampoco era correcto considerar que los testigos de las informaciones eran suficientes para dar valor al matrimonio. La constitución llegaba incluso a establecer que, siempre que se encontrara una partida de matrimonio en la que no se detallaran los testigos, se daría por nulo el mismo y se castigaría al cura responsable ${ }^{69}$.

\subsection{Los desposorios o matrimonio de presente}

La formación del matrimonio comenzaba con los desposorios o palabras de presente ${ }^{70}$. El catecismo de Trento recordó que las principales reglas o ritos para la celebración del matrimonio estaban ya en el decreto Tametsi ${ }^{71}$. A partir de ahí quedó reforzada la idea de que el otorgamiento mutuo era el que hacía el matrimonio, que podía luego tener diversas formas rituales ${ }^{72}$. Así fue recogido de forma explícita por el segundo concilio de Lima, donde se reiteró que la esencia del sacramento consistía en los consentimientos dados en presencia del párroco y de dos o tres testigos. Así, en el sermón XV del anexo a la Doctrina cristiana de 1585, se explicaba de este modo a los indígenas ${ }^{73}$ :

Este sacramento se celebra cuando el padre y cura vuestro os toma las manos a la puerta de la iglesia o en vuestra casa, diciendo el varón y la mujer que se quieren por

\footnotetext{
67 Machado de Chaves, 1646, vol. 1, pp. 601-602.

68 Peña Montenegro, 1995, vol. 2, pp. 250-253.

69 Debería pagar el coste de las informaciones para averiguar si hubo testigos, afrontar cuatro meses de prisión e incluso, en caso de rebeldía y desobediencia, admitir un coadjutor. La Paz 1738, cap. 3, ses. 7, cons. 7. Constituciones, 1970c.

70 Aznar Gil, 1992, p. 209; Gaudemet, 1993, p. 409.

71 Catechismus ad parochos, 1566, pte. II, cap. VIII, n. 28.

72 AzNAR GIL, 1992, pp. 275-287.

73 Segundo concilio de Lima, 1567-1568, pte. 1, cap. 16. Aznar GiL, 1992, pp. 209-210.
} 
marido y mujer. Entonces se hace este sacramento y no antes ni después; y todo lo demás que se hace, de velaros y de las arras y de las candelas y misa y todas son ceremonias y bendiciones de la Sancta Iglesia para que vuestro casamiento tenga buen suceso en servicio de Dios. Más cuando el varón y mujer por mano del cura, con testigos, os toma las manos, entonces se hace matrimonio y es sacramento de Jesucristo, en el cual os dan gracia del cielo para que estéis en servicio de Dios y seáis buenos casados y llevéis bien las cargas del matrimonio y os salvéis ${ }^{74}$.

Los desposorios podían celebrarse en las casas particulares o en la puerta de la iglesia. Trento propició que las bodas se trasladaran del ámbito privado al público ${ }^{75}$ y en el virreinato peruano ya lo recomendaron el primer y tercer limenses ${ }^{76}$; para la Nueva España y el Perú lo recogieron autores como Mentrida y Pérez Bocanegra respectivamente ${ }^{77}$; de hecho, acabó siendo lo más habitual, aunque se continuó celebrando excepcionalmente en casas particulares ${ }^{78}$. En ambos casos, el párroco debía acudir revestido con sobrepelliz y estola blanca e ir acompañado de otro clérigo o ministro que llevara el acetre y aspersorio para el agua bendita ${ }^{79}$. Los novios, a su vez, debían presentarse, preferiblemente, acompañados por padres y familiares ${ }^{80}$.

La peculiaridad indiana vino dada, no tanto por el ritual como por la introducción de las lenguas aborígenes en el caso de matrimonios de indígenas. Así, utilizando la lengua propia del lugar, lo primero que debía hacer el sacerdote, tras recordar brevemente los frutos del matrimonio, era mencionar de nuevo las amonestaciones para que los novios, testigos o personas presentes pudiesen dar a conocer, si era el caso, los impedimentos existentes. Oré en su Ritual peruano recomendaba dirigirse a los indígenas de forma directa: "Yo os requiero y os mando que si tenéis algún impedimento para casaros (...) lo manifestéis y os vais de aquí" 81 . Acto seguido, se aconsejaba que el sacerdote explicara muy brevemente los frutos del matrimonio ${ }^{82}$.

Tras este preámbulo, se pasaba a la parte central del rito: el intercambio de los consentimientos. Según recordaba Pérez Bocanegra, era preciso que al menos se expresaran con señales exteriores visibles ${ }^{83}$, sin embargo años después el Sínodo de Are-

74 Doctrina cristiana y catecismo para instrucción de los indios y de las demás personas que han de ser enseñadas en nuestra Santa Fe con un confesionario y otras cosas necesarias para los que los doctrinan, que se contienen en la página siguiente. Compuesto por autoridad del concilio provincial que se celebró en la ciudad de los Reyes, el año de 1583 y por la misma traducido en las dos lenguas generales de este Reino: quichua y aymara. Impreso con licencia de la Real Audiencia, en la ciudad de Los Reyes, por Antonio Ricardo primero impresor en estos reinos del Pirú. Año de 1585 , pp. $83 \mathrm{v}-88 \mathrm{v}$.

75 Cristellon - Seidel Menchi, 2011, p. 283. Sobre las diversas formas de celebración vigentes en la Edad Media y los esfuerzos unificadores de la Iglesia ver: BRUNDAGE, 2011, pp. 21-41.

76 En concreto lo aconsejaba para los indígenas "para que entiendan la grandeza del sacramento", Primer Concilio de Lima, 1551-1552, pte. 1, cons. 20. VARGas UGARTE, 1951; ver también: Tercer Concilio de Lima, 1582-1583, act. 2, cap. 37. VARGAS UGARTE, 1951.

77 Mentrida, 1630, pp. 590-592.

78 Ambas posibilidades aparecen en ZÁrate, 1734, fs. 38-39v; VenEGas, 1731, p. 114.

79 Mentrida, 1630, pp. 92-93; Venegas, 1731, p. 114; Pérez Bocanegra, 1631, pp. 590-592.

80 Pérez Bocanegra, 1631, pp. 592-599; Venegas, 1731, p. 114.

81 ORÉ, 1607, p. 210.

82 Mentrida, 1630, p. 92.

83 Pérez Bocanegra, 1631, pp. 590-592. 
quipa de 1684 , dispuso que se manifestara con palabras claras y no por signos ${ }^{84}$. Esto último fue de hecho lo habitual, que se usaran diversas fórmulas orales, que variaron según los usos recogidos en los distintos rituales que circularon por el virreinato.

Así, el Brevis forma administrandi de Zárate (1583), que como se ha mencionado tuvo una amplia difusión en Indias y fue muy reeditado, precisaba que el cura debía dirigirse en primer lugar a la mujer con las siguientes palabras: "Señora N., ¿otorgaste por mujer y esposa legítima por palabras de presente del señor N., que aquí está presente, como lo manda nuestra Santa Madre Iglesia Católica Romana?», a lo que debía responder: "Sí otorgo"; en segundo lugar le preguntaba: “¿Quiérele por su marido y esposo legítimo?", a lo que contestaba: "Sí quiero"; finalmente le interrogaba: “¿Recíbele por su marido y esposo?”, a lo que la mujer replicaba: "Sí recibo”; idénticas preguntas se formulaban después al varón ${ }^{85}$. El Rituale seu manuale peruanorum de Oré (1607), recogía las tres preguntas y respuestas a los cónyuges en términos muy parecidos, traduciéndolas también al quechua, aymara, puquina y guaranín ${ }^{86}$.

Para el resto del siglo XVII, la mayor parte de los rituales se adaptaron a los cambios introducidos por el Ritual Romano de 1614, en el que se interrogaba primero al hombre y se simplificaba el intercambio de consentimientos a una sola pregunta. Un ejemplo es el Ritual formulario de Pérez Bocanegra (1631) ${ }^{87}$. A pesar de la introducción del Ritual, la costumbre hispana mantuvo tanto en la península como en las Indias, las tres preguntas ${ }^{88}$.

Una vez manifestada la voluntad de ambos, los novios unían sus manos derechas ${ }^{89}$ y el sacerdote autorizaba el sacramento diciendo, habitualmente, la fórmula: "Ego coniungo vos in matrimonium in nomine Patris \& Filii \& Spiritus Sancti. Amen" y realizando la señal de la cruz sobre los casados para acabar rociándolos con agua bendita ${ }^{90}$. Pérez Bocanegra recomendaba usar esta fórmula o la que fuera costumbre en cada lugar sin traducirla al quechua, por ser solo parte del ritual y no propiamente de la celebración del matrimonio ${ }^{91}$.

\subsection{Las velaciones}

Las velaciones o bendiciones nupciales eran la última etapa de esta forma canónica tridentina. De hecho, hasta ese momento no se consideraba culminada la recepción del sacramento y no debía haber relaciones sexuales entre los casados $^{92}$. Si en la

\footnotetext{
84 Sínodo de Arequipa, 1684, tit. 10, cap. 10. Constituciones, 1971.

85 ZÁrate, 1734, fs. 39-39v. Molina, 1984, fs. 57-58, en su manual novohispano de 1569, proponía ya hacer una sola pregunta a ambos contrayentes.

86 ORÉ, 1607, pp. 210-215.

87 Pérez Bocanegra, 1631, pp. 590-592. Otros ejemplos son: Mentrida, 1630, p. 92; Palafox y MenDOZA, 1864, p. 133.

88 VeneGas, 1731, pp. 114-116.

89 Según algunos autores, este gesto se hacía antes del intercambio de consentimientos: MoLiNA, 1984, pp. 57-58; ORÉ, 1607, pp. 210-215.

90 Mentrida, 1630, pp. 92-93. Recogen otras variantes: MolinA, 1984, pp. 57-58; OrÉ, 1607, pp. 210215; ZÁRATE, 1734, fs. 39-39v.

91 Pérez Bocanegra, 1631, pp. 590-592 y 624-630.

92 Concilio de Trento, sesión 24, De refomatione circa matrimonium, cap. 1. AzNAR GiL, 1992, p. 209.
} 
Península la Iglesia trató de impedir la cohabitación previa a las bendiciones, que se castigaba en las sinodales ${ }^{93}$; con mayor motivo fue preciso incidir en este aspecto en el territorio americano, debido al peso de las prácticas matrimoniales precolombinas en los indígenas, a la laxitud moral con la que vivían muchos españoles y a la amplitud del territorio, que facilitaba la relajación de costumbres.

Por este motivo, los rituales de los siglos XVI y XVII recomendaban que al final del matrimonio de presente o desposorios el sacerdote exhortara a los casados a no vivir juntos hasta que recibieran las bendiciones de la Iglesia ${ }^{94}$. La misma advertencia se encuentra, por ejemplo, en sínodos andinos como los de Huamanga de 1629 y 1672 , dirigida a contrayentes procedentes de distintos grupos sociales ${ }^{95}$. No obstante, parece que la Iglesia fue en un principio más flexible en este punto con la población autóctona. Así, autores novohispanos como Alonso de la Veracruz (1599) y Alonso de Mentrida (1630) consideraban que, en el caso de los indígenas, esta convivencia previa no era causa de pecado grave ${ }^{96}$.

En lo referente a los plazos, se optó para los naturales por la unión de las dos ceremonias cuando la liturgia lo permitiera ${ }^{97}$. Este sistema se generalizó en las archidiócesis de Lima y La Plata en los siglos XVI y XVII, al igual que en otros territorios indianos ${ }^{98}$. Los concilios y sínodos andinos recomendaron la realización de desposorios y velaciones en el mismo día si era posible. Con esta continuidad se trató de evitar, tanto la cohabitación previa a las bendiciones, como la separación de los cónyuges desposados por entender que no estaban «plenamente» casados. Indicaciones en este sentido habían sido ya promulgadas por el primer y segundo limenses ${ }^{99}$ y recogidas en sínodos tan tempranos como el de Quito de $1570^{100} \mathrm{y}$ el de Tucumán de $1597^{101}$. También los tratadistas defendieron este uso: Mentrida aconsejaba a los párrocos procurar la «santa y loable costumbre» de que se celebrara el matrimonio de los indígenas en la iglesia y que, inmediatamente después, los casados recibieran las bendiciones nupciales ${ }^{102}$. Lo mismo aconsejaba Pérez Bocanegra, aunque reconocía que a veces era difícil velarlos seguidamente, bien porque se ausentaban, bien porque retrasaban el momento con diferentes preparativos «comprar candelas, hacer chicha

93 Constituciones sinodales de Pamplona, 1591, Libro 4, cap. 5, De sponsalibus et matrimoniis, "Que los desposados no cohabiten hasta que se velen y reciban las bendiciones nupciales". UsunÁRIZ GARAYOA, 2004, p. 303.

94 ZÁrate, 1734, pp. 39-39v; Mentrida, 1630, p. 82; PÉrez Bocanegra, 1631, p. 587.

95 Sínodo de Huamanga, 1629, tit. 3, cons. 5. Constituciones, 1970a; Sínodo de Huamanga, 1672, cap. 17. Constituciones sinodales del Obispado de la ciudad de Huamanga, celebradas en concilio diocesano por el ilustrísimo y reverendísimo señor doctor don Cristóbal de Castilla y Zamora en el mes de junio de 1672. En los Reyes. Impreso por Gerónimo de Contreras, 1677.

96 Veracruz, 2009, p. 237; Mentrida, 1630, p. 82.

97 Estaba prohibido celebrar las velaciones desde el primer domingo de Adviento a Epifanía, ambos inclusive, y desde el miércoles de Ceniza a la octava de Pascua, inclusive. Por concesión de Pio IV se permitió durante 25 años velar a los indios en cualquier momento del año, el privilegio caducó en 1587. ZÁrATE, 1734, fs. 40-43v. Ver sobre estos tiempos también: AzNAR GiL, 1992, pp. 212-213.

98 AzNAR GiL, 1992, p. 210 menciona una normativa similar del tercer concilio de México (1585).

99 Primer concilio de Lima, 1551-1552, pte. 1, cons. 20 y Segundo concilio de Lima, 1567-1568, pte. 1, cap. 16 y pte. 2 , cap. 68. VARgas UGarte, 1951.

100 Sínodo de Quito, 1570, pte. 4, cons. 48. Mateos, 1968.

101 Sínodo de Tucumán, 1597, pte. 2, cons. 5. AranciBia - Dellaferrera, 1978.

102 MENTRIDA, 1630, p. 82. 
y otras cosas para sus bodas», de modo que algunos aprovechaban esta situación para no vivir con su mujer legítima o repudiarla alegando que no estaban casados ${ }^{103}$. Parece que, junto con estos inconvenientes, también los motivos económicos pesaron en estas decisiones pastorales: diversos sínodos andinos del XVII recomendaron unir desposorios y velaciones para ahorrar gastos ${ }^{104}$, especialmente si se trataba de negros o "gente pobre" 105 .

El Sínodo de La Paz de 1738 estableció que, si los desposorios se celebraban en días en que la liturgia no permitía dar las bendiciones, los indígenas se velaran en los dos meses siguientes ${ }^{106}$. Los plazos fijados por la Iglesia indiana entre desposorios y velaciones variaron en los distintos territorios desde algunos días a varios meses, según mostró ya Aznar Gil ${ }^{107}$. Así, en el ámbito del Virreinato peruano se establecieron intervalos que iban desde los seis días, en el Sínodo Santiago Chile de 1688, a los seis meses en los sínodos de Trujillo 1624 y Huamanga de 1629 y $1672^{108}$. Soluciones intermedias, que daban un tope de dos y tres meses para recibir las bendiciones, fueron las más frecuentes: estos tiempos fueron los establecidos, por ejemplo en el Sínodo de Concepción de 1744 donde, al denunciarse la práctica extendida de que los cónyuges vivieran juntos durante meses y años sin velarse, se confirmaba la pervivencia temporal de esta trasgresión ${ }^{109}$. Lo interesante es que la mayor parte de estas constituciones tenían ya un carácter general para todos los grupos sociales, lo cual confirmaría que la tendencia a unir las dos ceremonias se hizo extensiva a todos los fieles, siguiendo la recomendación de autores andinos como Peña Montenegro ${ }^{110}$. Por otro lado, este acortamiento de los tiempos entre desposorios y velaciones estuvo en consonancia con lo que ocurrió también en algunos lugares de Europa ${ }^{111}$.

La ceremonia de las velaciones debía tener lugar de día ${ }^{112}$, en la propia parroquia. Esto último quedó ya recogido con claridad en los concilios limenses ${ }^{113}$. De ahí pasó

103 Pérez Bocanegra, 1631, pp. 592-599 y 624-630.

104 Sínodo de Arequipa, 1684, tit. 10, cap. 15. Constituciones, 1971.

105 Sínodo de Lima, 1613, lib. 4, tit. 1, cap. 10. Soto Rábanos, 1987; Sínodo de Trujillo, 1624, act. 4, cap. 2. Constituciones sinodales del Obispado de Trujillo del Perú (...), AGI, Lima 307; Sínodo de Huamanga, 1629 , tit. 3, const. 5, Constituciones, 1970a; Sínodo de Huamanga, 1672, cap. 17, cons. 14, Constituciones sinodales del Obispado de la ciudad de Huamanga, 1672. En los Reyes. Impreso por Gerónimo de Contreras, 1677.

106 Sínodo de La Paz, 1738, cap. 3, ses. 7, cons. 17. Constituciones, 1970c.

107 AzNAR GiL, 1992, pp. 210-211.

108 Sínodo de Santiago, 1688, cap. 4, cons. 11. Sínodos, 1983; Sínodo de Trujillo, 1624, act. 4, cap. 2. Constituciones sinodales del Obispado de Trujillo del Perú (...), AGI, Lima 307; Sínodo de Huamanga, 1629 , tit. 3, cons. 5. Constituciones, 1970a; Sínodo de Huamanga, 1672, cap. 17, cons. 14. Constituciones sinodales del Obispado de la ciudad de Huamanga, 1672. En los Reyes. Impreso por Gerónimo de Contreras, 1677.

109 Sínodo de La Concepción, 1744, cap. 5, cons. 12. Sínodo, 1984. También establecían plazos de tres meses el sínodo de Cuzco, 1601, cap. 29. AnAlectes, 1831; el sínodo de Arequipa, 1638, lib. 2, tit. 8, cap. 8. Constituciones sinodales del Obispado de Arequipa, BNE; el Sínodo de Arequipa, 1684, tit. 10, cap. 15. Constituciones, 1971; el Sínodo de Santiago de Chile, 1763, tit. 8, cons. 12. SínOdos, 1983.

110 Peña Montenegro, 1995, vol. II, p. 197.

111 Por ejemplo en la diócesis de Florencia, ver Lombardi, 1996, pp. 240-241.

112 Sínodo de Lima, 1613, lib. 4, tit. 1, cap. 11 en Soto Rábanos, 1987; Sínodo de Huamanga, 1629, tit. 3, cons. 5. Constituciones, 1970a; Sínodo de Huamanga, 1672, cap. 17, n. 15. Constituciones sinodales del obispado de la ciudad de Huamanga, 1672. En los Reyes. Impreso por Gerónimo de Contreras, 1677; Sínodo de Arequipa, 1684, tit. 10, cap. 15. ConstituCIONES, 1971.

113 Primer Concilio de Lima, 1551-1552, pte. 2, cons. 69. VARgas UGarTe, 1951. Esta disposición se reitera en el Segundo Concilio de Lima, 1567-1568, pte. 1, cap. 16 y en el Tercer concilio de Lima, 1582-1583, act. 
a los sínodos de los territorios de Lima y Charcas que fueron reiterativamente explícitos en este punto, prohibiendo la celebración de las bendiciones fuera de las parroquias ${ }^{114}$. Por ejemplo, los padres sinodales reunidos en Arequipa en 1684 lamentaron la facilidad con que se celebraban velaciones en otros lugares, en contra de lo dispuesto por el Ritual Romano, y recordaron que era algo excepcional que sólo podía hacerse con licencia del obispo. En términos muy parecidos se incluyó también esta advertencia en las sinodales de La Paz de 1738, pero dirigida exclusivamente a españoles, recordando que no se debían hacer excepciones "por nobles y privilegiados que sean sus dueños": la iglesia era el lugar adecuado por ser casa de oración y, además, la solemnidad de las ceremonias fomentaba la devoción de los fieles, mientras que, el no respetarla, favorecía una menor estimación y aprecio por el sacramento ${ }^{115}$. Tanto relieve se dio en este último sínodo a la solemnidad litúrgica de las bendiciones, que se estableció también que los curas de indios, al velarlos excepcionalmente en tiempos prohibidos, lo hicieran en la iglesia, con la misma dignidad en el culto que en circunstancias normales ${ }^{116}$. Autores como Alonso de la Veracruz, Alonso de Mentrida y Juan Pérez Bocanegra trataron también la necesaria celebración de las bendiciones dentro de la iglesia parroquial ${ }^{117}$.

La Iglesia rodeó las bendiciones nupciales de un rito en el que gestos y palabras recalcaban la importancia del sacramento. De ahí que diferentes concilios y sínodos indianos insistieran también en el adorno del templo y el decoro con que debían vestir los cónyuges, que acudirían a las bendiciones portando velas y ofrendas ${ }^{118}$.

Con respecto al ritual de las velaciones, el arcediano de Trujillo, Juan Machado de Chaves, destacaba en su Perfecto confesor, la antigüedad de la ceremonia, a la que se habían referido ya muchas veces los padres de la Iglesia y numerosos concilios ${ }^{119}$. El modo de celebrar esta segunda etapa del matrimonio acabó fijándose, también en Indias, a partir de la publicación del Ritual Romano, aunque durante un tiempo convivieran las nuevas formas con rituales anteriores. Prueba de ello es que el concilio de La Plata de 1629 permitió utilizar los rituales Toledano y Mexicano si faltaba el Romano ${ }^{120}$.

La primera parte de esta ceremonia tenía lugar en la puerta del templo. En este caso, la única modificación introducida por el Ritual Romano fue que el sacerdote saliera revestido a la puerta de la iglesia, donde le esperaban los novios ${ }^{121}$. Esta novedad

2, cap. 34. VARgas UGarte, 1951.

114 Sínodo de Cuzco, 1601, cap. 29. Analectes, 1831; Sínodo de Arequipa, 1638, lib. 2, tit. 8, cap. 8. Constituciones sinodales del Obispado de Arequipa, BNE; Sínodo de Lima, 1636, Titulo de officio rectoris, cap. 11. Soto Rábanos, 1987, pp. 25-26.

115 Sínodo de Arequipa, 1684, tit. 10, cap. 15. Constituciones, 1971; Sínodo de La Paz, 1738, cap. 3 , ses. 7 , cons. 9 y 21 .

116 Sínodo de La Paz, 1738, cap. 3, ses. 7, cons. 15. Constituciones, 1970c.

117 Mentrida, 1630, p. 82; Veracruz, 2009, pp. 217-225; Pérez Bocanegra, 1631, pp. 588-589.

118 AzNar Gil, 1992, pp. 213-214. Molina, 1984, pp. 57-58: "Traigan candelas de cera y sus personas con vestiduras limpias a la iglesia".

119 Machado de Chaves, 1646, vol. 2, p. 574.

120 Concilio de La Plata, 1629, p. 104. Velasco, 1964.

121 García Alonso, 1959, pp. 360-365. 
fue ya recogida por Palafox y por Venegas ${ }^{122}$ para el Virreinato de la Nueva España y por Pérez Bocanegra para el del Perú ${ }^{123}$.

Una vez allí, lo primero que se hacía era contar las arras, que debían ser trece monedas de oro y plata, que se colocaban en una bandeja pequeña junto con los anillos -también de oro o de plata-. El sacerdote bendecía primero las arras y luego los anillos y procedía a la aspersión de agua bendita sobre ellos y sobre los presentes. A continuación, tomando un anillo con los tres primeros dedos y recitando la fórmula establecida, lo introducía en dedo anular del esposo diciendo la oración de la señal de la cruz. Después daba el otro anillo al esposo, quien sujetándolo también con tres dedos, se lo ponía a la esposa en el mismo lugar, mientras el sacerdote repetía la misma oración. Luego, puestas las manos de la mujer juntas con las palmas hacia arriba, debajo de las del hombre, este dejaba caer las arras diciendo: "Esposa este anillo y arras os doy en señal de mi matrimonio"; a lo que ella respondía: "yo lo recibo". El sacerdote rezaba entonces las oraciones recogidas en el Ritual y tomando después las manos derechas de los esposos, los introducía en el templo mientras incoaba el Salmo $127^{124}$.

Así, precedidos del cura y sus ministros, entraban en el templo los novios y se colocaban delante de las gradas del altar, donde se arrodillaban y el sacerdote recitaba de nuevo las oraciones que indicaba el Ritual ${ }^{125}$. A continuación entraba en la sacristía donde se quitaba la capa y salía revestido con casulla y manípulo ${ }^{126}$ blancos para celebrar la Misa "Pro sponso et sponsa" del Misal Romano, según establecía el decreto tridentino ${ }^{127}$. Los novios y sus padrinos encendían, después del "Sanctus", las velas que llevaban. El momento de las bendiciones tenía lugar tras el "Pater noster". El párroco se situaba de pie, en el lado del Evangelio, desde donde rezaba -con las manos abiertas- las oraciones prescritas, estando los esposos arrodillados delante del $\operatorname{altar}^{128}$.

La costumbre hispana, recogida en el Manual Toledano, establecía que, antes de decir estas oraciones, el párroco cubriera con un velo de seda blanco y rojo -colores alusivos a la pureza y la procreación- la espalda del marido y la cabeza de la esposa y,

122 Palafox y Mendoza, 1864, pp. 140-148; Venegas, 1731, p. 117.

123 PÉrez BocAnegra, 1631, pp. 592-599, 624-630.

124 "Las cuales palabras ha de decir cada desposado en su lengua que su esposa las entienda". MENTRIDA, 1630, pp. 93-96.

125 ZÁrate, 1734, fs. 40-43v; Pérez Bocanegra, 1631, pp. 592-599, 624-630; Oré, 1607, pp. 216-219, recogía lo mismo que Zárate pero en latín. Bocanegra mencionaba un solo anillo y aconsejaba que fuera de plata, a pesar de la pobreza de los curatos de indios: PAlafox y MendozA, 1864, pp. 140-148, describía un ritual muy semejante a los tres primeros con la diferencia de que era la esposa la que primero recibía el anillo y luego lo ponía al esposo; este autor incluía las fórmulas en nahuatl. VenEGAs, 1731, p. 117; MENTRIDA, 1630, pp. 93-98.

126 Según el Diccionario de Autoridades era un ornamento semejante a la estola pero más pequeño que el sacerdote se ceñía en el brazo izquierdo, sobre el alba. Simbolizaba las ataduras de Cristo durante la flagelación.

127 Si el día de la boda era domingo o festivo se decía la misa de la fiesta con conmemoración de la de las velaciones. Al respecto de esta y otras posibilidades es muy completo el manual de PALAFOX y MENDOZA, 1864, pp. 151-154.

128 Mentrida, 1630, pp. 98-101; Pérez Bocanegra, 1631, pp. 592-599, 624-630; Venegas, 1731, pp. 117, 121-122; ZÁrate, 1734, fs. 40-43v; OrÉ, 1607, pp. 219-222; Palafox y Mendoza, 1864, pp. $140-148$. 
donde fuera costumbre, colocara un "yugal" o cadena sobre los hombros de ambos ${ }^{129}$. Entre los manuales indianos consultados, solo los rituales de Palafox y de Venegas, que presumiblemente circularon solo en la Nueva España, incorporan este último rito $^{130}$. Todo parece indicar que no se introdujo en el ámbito andino.

Por último, antes de dar la bendición final de la misa, el sacerdote se volvía hacia los esposos y los bendecía con una oración específica ${ }^{131}$. Después, -si era el caso- les quitaba el velo y el "yugal". Finalmente, les encomiaba a guardarse lealtad mutua, a quererse y a amar la virtud de la castidad. Vuelto al altar, les daba otra bendición y leía el prólogo del evangelio de San Juan. Los novios y padrinos ofrecían entonces las candelas que llevaban, que seguían encendidas ${ }^{132}$.

Tanto Oré como Pérez Bocanegra recogen la costumbre final de que el cura, pidiendo a los novios que se tomaran las manos derechas, entregara la mujer al marido diciendo: "Esposa os doy y no sierva, amadla como Cristo a su Iglesia" 133 . El segundo autor deja constancia de la aceptación que esta práctica tuvo entre los indígenas andinos hasta el punto que si se suprimía "les parecería les habían quitado una de las ceremonias de la celebración del matrimonio" 134 . Era en las velaciones donde se desarrollaba más el Toledano: ni el anillo que el esposo daba a la esposa, ni las arras, ni la imposición del yugal estaban en el Romano ${ }^{135}$.

En el caso de segundas bodas de la mujer, no del varón, las velaciones se simplificaban porque se consideraba que la novia estaba ya bendecida, fuera virgen o no. Se omitía el rito de las arras y los anillos ${ }^{136}$ y el del velo y "yugal"; tampoco se decía la misa de bodas sino la que correspondía, que se ofrecía por los nuevos esposos, quienes la oían separados de la grada del altar ${ }^{137}$. Pérez Bocanegra aconsejaba explicar bien a los indígenas el rito de segundas nupcias para aclarar que era tan válido como el de las primeras: “... siendo estos indios gente tan nueva en la fe y tan ceremonial en todas sus acciones y que entienden que no dándoles en las segundas bodas todo lo que en las primeras, no quedan casados" 138 .

129 García Alonso, 1958, pp. 404-414 y 1959, pp. 360-365. La palabra "yugal” no aparece en el $D R A E$, sin embargo recoge para la palabra "yugo" esta acepción: "velo (que se ponía a los desposados en la misa de velaciones)". Palafox en su Manual habla de "yugal" o cadena, acepción que estaría más de acuerdo con la definición que da Covarrubias en su Tesoro. Anillos, velo y una tira de tela que simbolizaba la unión o atadura de los novios fueron ya introducidas en Europa en el ritual matrimonial por el Decreto de Graciano. CRISTELLON - SEIDEL MENCHI, 2011, pp. 279-280.

130 Molina, 1984, pp. 57-58; Palafox y Mendoza, 1864, pp. 140-148; Venegas, 1731, pp. 121-122.

131 Mentrida, 1630, p. 101.

132 Mentrida, 1630, p. 101; Palafox y Mendoza, 1864, pp. 140-148; Venegas, 1731, pp. 121-122; PÉrez BocANEGRA, 1631, pp. 592-599 y 624-630, recogía una “Amonestación a los casados en romance”, traducida también al quechua.

133 OrÉ, 1607, pp. 219-222; PÉrez BocANEGRA, 1631, pp. 592-599; VENEGAS, 1731, pp. 121-122.

134 PÉrez BocANeGRA, 1631, pp. 592-599 y 624-630.

135 Borobio García, 1993, pp. 70-73 y 114.

136 PÉrez Bocanegra, 1631, pp. 592-599 y 624-630, se mostraba más flexible entendiendo que la bendición de arras y anillos sí se podía repetir.

137 ZÁrate, 1734, pp. 46-47; Mentrida, 1630, pp. 84-85; PAlafox y MendozA, 1864, pp. 150-151; VeNEGAS, 1731, pp. 123-124.

138 PÉrez Bocanegra, 1631, pp. 592-599, 624-630. 


\subsection{Derechos, limosnas y registro parroquial}

En América ya estaba previsto que no se cobraran a los indígenas derechos por la administración de los sacramentos, las sinodales incidieron en general en este punto, en algunos casos con referencia concreta al matrimonio. Tan solo se admitían limosnas voluntarias en la misa nupcial. Esta disposición se hizo extensiva a mestizos, cuarterones, negros libres y esclavos ${ }^{139}$. También se estableció que en las parroquias de indios hubiera arras y anillos que pudieran ser reutilizados en las diferentes celebraciones, con el fin de evitar a los indígenas este desembolso ${ }^{140}$.

Finalmente, para la precisa publicidad de la nueva forma canónica, debía quedar constancia por escrito del matrimonio contraído ${ }^{141}$. Con ese fin, los párrocos eran responsables de custodiar bajo llave el Libro de matrimonios y mantenerlo actualizado. En él debían anotar tanto los desposorios como las velaciones, detallando los nombres y naturaleza de los contrayentes y de sus padres, del cura, testigos y padrinos -quienes, a su vez, debían firmar debajo-. Igualmente tenía que constar la fecha y lugar en que se había contraído el matrimonio. Convenía recoger estos datos de forma inmediata, aunque hubiera muchos matrimonios en un mismo día, "sin fiarlo a la memoria". Cuando se casaba a parroquianos ajenos, se debía enviar un traslado al otro cura párroco para que anotara el matrimonio en su libro ${ }^{142}$. De hecho son precisamente estos libros de matrimonios la mejor fuente para comprobar cómo se celebró en Indias el matrimonio, siguiendo lo estipulado por Trento. En ellos, como es conocido, se hace referencia a las informaciones -en los casos en que ha sido preciso recabarlas de otros lugares-, se da cuenta de la publicación de amonestaciones o de su dispensa, se incluyen las fechas de desposorios y velaciones -con un registro para cada uno si son en días distintos- y se aporta la información mencionada sobre los contrayentes,

139 Sínodo de Cuzco, 1601, caps. 3 y 37. Analectes, 1831; Sínodo de La Plata, 1619-1620, tit.4, cap. 18. BARnADAS, 2002; Sínodo de La Plata, 1628, In titulo de officio rectoris, cap. 18. Constituciones sinodales del arzobispado de la ciudad de La Plata, 1628. En los Reyes. Impreso por Gerónimo de Contreras, 1629; Sínodo de Huamanga, 1629, tit. 3, cons. 4. Constituciones, 1970a; Sínodo de Santiago de Chile, 1626, p. 30. Oviedo Cavada, 1971; Sínodo de Lima 1636, "Titulo de Officio Rectoris”, cap. 4. Soto Rábanos, 1987, pp. 21-22; Sínodo de Arequipa, 1638, lib. 2, tit. 8, cap. 8. Constituciones sinodales del obispado de Arequipa, BNE; Sínodo de La Concepción, 1744, cap. 5, cons. 14. SínOdo, 1984; MenTridA, 1630, p. 98.

140 Sínodo de Lima, 1594; Sínodo de Quito, 1596, cons. 17 y 32; Sínodo de Lima, 1596, 142. ComPENDIO, 1606; Sínodo de Lima, 1613, tit. 3, cap. 7, Soтo RÁBAnos, 1987; Sínodo de Huamanga, 1629, tit. 3, cons. 4. Constituciones, 1970a; Sínodo de Arequipa, 1638, lib. 2, tit. 8, cap. 8. Constituciones sinodales del Obispado de Arequipa, BNE. AzNar GiL, 1992, pp. 213-214.

141 GAUDEMET, 1993, p. 347.

142 Segundo Concilio de Lima, 1567-1568, pte. 1, cap. 18. VArgas UGarte, 1951; Sínodo de Lima, 1585, cap. 17; Sínodo de Lima, 1586, caps. 3 y 7; Sínodo de Lima, 1596, cons, 35, 81, 86; Sínodo de Tucumán, 1597, pte. 2, cons. 18; Sínodo de Asunción, 1603, pte. 2, cons. 15. Dellaferrera - Martini, 2002; Sínodo de Lima, 1604, caps. 4 y 7; Sínodo de Lima, 1613, lib. 4, tit. 1, cap. 8. Soto RÁBAnos, 1987; Sínodo de La Plata, 16191620, tit. 4, cap. 10. Barnadas, 2002; Sínodo de Huamanga, 1629, tit. 3, cons. 6. Constituciones, 1970a; Sínodo de La Paz, 1638, lib. 1, tit. 5, cap. 6. Constituciones, 1970b; Sínodo de Arequipa, 1638, lib. 2, tit. 8, cap. 1. Constituciones sinodales del Obispado de Arequipa, en BNE; Sínodo de Huamanga, 1672, caps. 17 y 22. Constituciones sinodales del Obispado de la ciudad de Huamanga, 1672. En los Reyes. Impreso por Gerónimo de Contreras, 1677; Sínodo de Arequipa, 1684, tit. 10, cap. 8 (incluye un modelo). ConsTiTUCIONES, 1971; Sínodo de La Paz, 1738, cap. 3, ses. 7, const. 1. Constituciones, 1970c; Sínodo de La Concepción, 1744, cap. 5, cons. 19. SínOdo, 1984. Los sínodos de Lima citados están en CoMPENDIO, 1606. También incorporaban instrucciones al respecto los manuales de párrocos de: MenTRIDA, 1630, p. 102; VenEGAS, 1731, pp. $115-116$. 
el oficiante y los testigos. No es de extrañar que los párrocos los guardaran bajo llave y que los visitadores eclesiásticos les prestaran una especial atención.

Por lo tanto, al igual que en la fase previa, también en la celebración del matrimonio se impuso la normativa tridentina sobre la presencia del propio párroco, acompañado de testigos que asistieran, entendiendo lo que ocurría, al intercambio del consentimiento o desposorios. El ritual de este "matrimonio de presente" y de las posteriores bendiciones o velaciones se aplicó igualmente siguiendo la forma hispana -no incorporada por completo al ámbito andino- a través sobre todo del Manual toledano postridentino y del llamado Manual Mexicano Pequeño y, por supuesto, a través de la reforma tridentina del Ritual de 1614, plasmado en el ámbito andino en la obra de Pérez Bocanegra.

\section{CONCLUSIONES Y PERSPECTIVAS}

El análisis de los textos conciliares y sinodales así como de los manuales de sacramentos, rituales y confesionarios del ámbito andino ofrece la posibilidad de reconstruir los ritos de celebración del matrimonio. Es destacable la rápida incorporación de la normativa tridentina en la materia, especialmente a partir de la publicación del Ritual Romano de 1614, un texto globalizador en lo que a ceremonial se refiere. No obstante, en un futuro trabajo el tema se abordará a partir de visitas eclesiásticas, que permitan indagar más sobre el terreno esta aplicación.

En definitiva, es posible encontrar en estas fuentes una casuística peculiar andina en la implantación del matrimonio, que vino condicionada, por la tradición hispana $\mathrm{y}$, sobre todo, por la especial atención prestada a la población indígena con el fin de facilitar la implantación del modelo matrimonial cristiano. Esto último se trató de lograr, por ejemplo, mediante una mayor flexibilidad en el cumplimiento de los requisitos para el matrimonio -propia sobre todo de los siglos XVI y XVII- y la traducción de los rituales a las lenguas aborígenes. Con el paso del tiempo la tendencia fue, sin embargo, uniformadora: los indígenas pasaron, en general, a ser unos feligreses más a la hora de cumplir la normativa tridentina sobre la celebración del matrimonio.

\section{REFERENCIAS BIBLIOGRÁFICAS}

Albani, Benedetta

2009 "In universo christiano orbe: la Sacra Congregazione del Concilio e l'administrazione dei sacramenti nel Nuovo Mondo (secoli XVI-XVII)". Mélanges de l'Ecole française de Rome. Roma, nº 121/1, pp. 63-73.

Alloza, Juan de

1665 Flores summarum, seu Alphabetum morale: omnium fere casuum qui confessoribus contingere possunt, ex selectioribus doctoribus prcecipuè Societatis Iesu, ex utroque iure, ac manuscriptis peruanis. Opus sedulo labore per annos triginta conquisitum, ex legibus imperatorum, decretis pontificum, usu parochorum, \& prcetorum huius peruani regni. Leodii, Impensis Ioannis de A Costa Bibliopolæ Vlyssiponensis. 


\section{ANALECTES}

1831 ---- o colección de varias piezas anécdotas pertenecientes a la Santa Iglesia del Cuzco. Lo da a luz el doctor don Carlos Gallegos, cura propio de la doctrina de San Felipe de Caracoto y su anejo de San Juan Bautista de Huaca en el departamento de Puno. Cuzco. Colegio de Ciencias y Artes - Archivo Histórico Jesuita de la Escuela Superior Antonio Ruíz de Montoya de Lima, Colección Vargas Ugarte, vol. 9.

Arancibia, José M.

1972 "El matrimonio en los sínodos del obispo Trejo". Teología. Revista de la Facultad de Teología de la Pontificia Universidad Católica Argentina. Buenos Aires, n² 21, pp. 93-110.

Arancibia, José M. - Dellaferrera, Nelson C.

1978 Los Sínodos del antiguo Tucumán celebrados por Fray Fernando de Trejo y Sanabria 1597, 1606, 1607. Buenos Aires. Editora Patria Grande.

AzNAR GIL, Federico R.

1985 La introducción del matrimonio cristiano en Indias: aportación canónica (s. XVI). Lección inaugural del Curso Académico 1985-1986. Salamanca. Universidad Pontificia de Salamanca.

1992 "La celebración del sacramento del matrimonio en las Indias". En Borobio (ed.), La primera evangelización de América: contexto y claves de interpretación. Salamanca. Universidad Pontificia de Salamanca, pp. 189-220.

1999 "Las amonestaciones o proclamas matrimoniales en los sínodos ibéricos medievales (siglos XIII-XVI)". En Fernández (ed.), Sínodos diocesanos y legislación particular: estudios históricos en honor al Dr. D. Francisco Cantelar Rodríguez. Salamanca. Universidad Pontificia de Salamanca, pp. 135-160.

BARnadas, Josep M.

1967 “El sínodo de La Paz de 1738”. Missionalia Hispánica. Madrid, no 24/70, pp. 117-124.

BARnADAS, Josep M. (ed.)

2002 Constituciones del I sínodo platense (1619-1620). Jerónimo Méndez de Tiedra. Sucre. Archivo-Biblioteca Arquidiocesanos Mons. Taborga.

Borobio García, Dionisio

1993 Inculturación del matrimonio. Ritos y costumbres matrimoniales de ayer y de hoy. Madrid. San Pablo.

BRUndage, James A.

2011 “"E pluribus unum': Custom, the Professionalization of Medieval Law, and Regional Variations in Marriage Formation". En Regional Variations in Matrimonial Law and Custom in Europe, 1150-1600. Leiden-Boston, Brill, pp. 21-41.

Catechismus

1566 ---- ad parochos: ex decreto Concilii Tridentini editus et Pii. V. Pont. Max. jussu promulgatus. Sincerus \& intiger, mendisque iterùm repurgatus opera P.D.L.H.P.; A quo est additus apparatus ad catechismum, in quo ratio, auctores, auctoritas, approbatores \& usus declarantur, Londini, Nathanaelem Thompson, in Vico Old-Spring-Garden dicto, 1687.

\section{COMPENDio}

1606 ---- sumario de los sínodos de los años de ochenta y dos y cuatro y ochenta y cinco, ochenta y seis y ochenta y ocho, noventa y dos y noventa y cuatro, hecho en este sínodo y constituciones sinodales del Ilmo. Sr. D. Toribio Alfonso de Mogrovejo, arzobispo de Los Reyes... John Carter Brown Library. 


\section{CONSTITUCIONES}

1970a ---- sinodales del Obispado de Huamanga, 1629 de Francisco Verdugo. Cuernavaca. CIDOC.

1970b---- sinodales del Obispado de Nuestra Señora de La Paz del Perú, 1638. Cuernavaca. CIDOC.

1970c ---- sinodales del Obispado de La Paz (Bolivia) 1738 establecidas por Agustín Rodríguez Delgado, obispo de la ciudad de Nuestra Señora de La Paz. Cuernavaca. CIDOC.

1971 ---- sinodales del Obispado de Arequipa, 1684. Hechas y ordenadas por Antonio de León su obispo. Cuernavaca. CIDOC.

1981 ---- sinodales fechas por (...) Luis López de Solís (...) obispo de Quito (...) en el año de 1594. Cuernavaca. CIDOC.

Charles, John

2010 Allies at odds: the Andean church and its indigenous agents, 1583-1671. Albuquerque. University of New Mexico Press.

Coello De La Rosa, Alexandre

2005 “Agencias políticas y políticas de santidad en la beatificación del padre Juan de Alloza, SJ (1597-1666)”. Hispania sacra. Madrid, nº 57/116, pp. 627-650.

Cristellon, Cecilia

2009 "Does the Priest Have to Be There? Contested Marriages Before Roman Tribunals. Italy, Sixteenth to Eighteenth Centuries". Österreichische Zeitschrift für Geschichtswissenschaften. Viena, $n^{\circ}$ 20/3, pp. 10-30.

Cristellon, Cecilia - Seidel Menchi, Silvana

2011 "Rituals Before Tribunals in Reinassance Italy: Continuity and Change, 1400-1600". En Korpiola (ed.), Regional Variations in Matrimonial Law and Custom in Europe, 1150-1600. Leiden-Boston. Brill, pp. 275-287.

Dellaferrera, Nelson C.

1999 "El matrimonio en las sinodales del obispo Trejo". Anuario Argentino de Derecho Canónico. Buenos Aires, $n^{\circ}$ 6, pp. 35-56.

Dellaferrera, Nelson C. - Martini, Mónica P.

2002 Temática de las constituciones sinodales indianas (s. XVI-XVIII). Arquidiócesis de La Plata. Buenos Aires. Instituto de Investigaciones de Historia del Derecho.

Donahue, Charles

2007 Law, Marriage, and Society in the Later Middle Ages. Cambridge. Cambridge University Press.

DurÁn, Juan Guillermo

1982 El catecismo del III Concilio Provincial de Lima y sus complementos pastorales: (1584-1585). Buenos Aires. El Derecho.

García Alonso, Ireneo

1958 "El Manual Toledano para la administración de sacramentos a través de los siglos XIV-XVI". Salmanticensis. Salamanca, no 5/2, pp. 351-450.

1959 "Edición tridentina del Manual Toledano y su incorporación al Ritual Romano". Salmanticensis. Salamanca, nº 6/2, pp. 323-399.

GARCía y García, Antonio

1992 “Las asambleas jerárquicas”. En Borges Morán (ed.), Historia de la Iglesia en Hispanoamérica y Filipinas (siglos XV-XIX). Vol. I: Aspectos generales. Madrid. Biblioteca de Autores Cristianos, pp. 175-192. 
GAUDEMET, Jean

1993 El matrimonio en Occidente. Madrid. Taurus.

LASSÈGE-MORÈLES, Juan B.

1987 “Sínodos diocesanos del Cusco 1591 y 1601”. Cuadernos para la Historia de la Evangelización en América Latina. $\mathrm{n}^{\circ}$ 2, pp. 31-72.

LATASA, Pilar

2005 "La celebración del matrimonio en el virreinato peruano: disposiciones en las archidiócesis de Charcas y Lima (1570-1613)”. En ArELLANO - UsunárIz (eds.), El matrimonio en Europa y el mundo hispánico: siglos XVI y XVII. Madrid. Visor Libros, pp. 237-256.

2008 "Publicidad y libertad en el matrimonio: autoridad paterna y dispensa de amonestaciones en Lima, 1600-1650”. En UsunÁRIZ - GARcía BourRellier (eds.), Padres e hijos ante el matrimonio: España y el Mundo Hispánico (siglos XVI-XVIII). Madrid. Visor Libros, pp. 53-67.

LOMBARDI, Daniela

1996 "Findazamenti e matrimoni dal Concilio di Trento alle riforme settecentesche". En DE Giorgio - Klapisch-ZubER (eds.), Storia del matrimonio. Roma. Laterza, pp. 215-250. 2001 Matrimoni di antico regime. Bologna. Il Mulino.

LUNDBERG, Magnus

2011 Church life between the Metropolitan and the Local Parishes, Parishioners, and Parish Priests in Seventeenth-Century Mexico. Madrid - Frankfurt. Iberoamericana Vervuert.

Machado de Chaves, Juan

1646 Perfecto confesor y cura de almas, asunto singular, en el qual con suma claridad, breve, y cientifico modo, se reducen a principios universales y reglas generales de ambos derechos, civil y canónico, todas las materias pertenecientes al teólogo moral... En Madrid, por la viuda de Francisco Martínez, 2 vols.

MATEOS, Francisco

1968 "Primer Concilio de Quito". Missionalia Hispánica. Madrid, no 25/75, pp. 319-368.

1969 "El primer Concilio del Río de la Plata en Asunción (1603)”. Missionalia Hispánica. Madrid. $n^{\circ} 78$, pp. 257-359.

MANNHEIM, Bruce

2012 "Leer a Juan de Pérez Bocanegra, su Ritual Formulario y Hanaq pachap kusikuynin". En 1631 Ritual formulario e institución de curas. Cusco. Facultad de Ciencias Sociales - Universidad Nacional San Antonio Abad del Cusco, pp. XXI-XXXVII.

Molina, Alonso de

1984 Confesionario mayor en la lengua mexicana y castellana [1569]. Roberto Moreno (ed.). México. Universidad Nacional Autónoma.

Mentrida, Alonso de

1630 Ritual para administrar los sanctos sacramentos sacado casi todo del Ritual romano y lo demás del Ritual Índico, con algunas advertencias necesarias para la administración de los santos sacramentos (...) Recopilado por Fr. Alonso de Mentrida, de la Orden de San Agustín, para servicio y uso de los ministros de su orden en estas Islas Philipinas. Manila. en el Colegio de Sancto Thomas por Thomas Pinpin y Iacinto Magarulau.

Morant Deusa, Isabel - Bolufer Peruga, Mónica

1998 Amor, matrimonio y familia: la construcción histórica de la familia moderna. Madrid. Síntesis. 
ORÉ, Luis Jerónimo de

1607 Rituale seu manuale peruanorum et forma brevis administrando apud indios sacrosancta baptismi, paenitentiae (...) Et quae indigent versione, vulgaris idiomatibus Indicis, secundum diversos situs omnium provinciarum novi orbis Peru. Neapoli, apud Io. Jacobum, Carlinum et Costantinum Vitales.

Oviedo Cavada, Carlos (ed.)

1971 Francisco González de Salcedo. Sínodo diocesano de Santiago de Chile, 1626. Cuernavaca. CIDOC.

PALAFOX y Mendoza, Juan de

1864 Manual para la precisa, pronta y fácil administración de los santos sacramentos, arreglada al ritual de nuestro Santísimo Padre Paulo V (...) Formado por orden del (...) señor don Juan de Palafox y Mendoza, mandado observar puntualmente así por dicho Venerable Sr. como por otros... obispos hasta nuestro actual gobernador de esta sagrada mitra (...) Manuel Ladrón de Guevara, obispo de Chiapa. Puebla. Tip. de J.M. Rivera.

Peña Montenegro, Alonso de la

1995 Itinerario para párrocos de indios. BACIERo - GArcía AÑoveros - MASEdA - CorraLES (eds.). Madrid. CSIC, 2 vols.

PÉrez Bocanegra, Juan

1631 Ritual formulario e instrucción de curas: para administrar a los naturales de este reino los sanctos sacramentos del baptismo, confirmación, eucaristía y viático, penitencia, extremaunción y matrimonio: con advertencias muy necesarias. Impreso en Lima por Gerónimo de Contreras.

RÍPODAs Ardanaz, Daisy

1977 El matrimonio en Indias: realidad social y regulación jurídica. Buenos Aires. Fundación para la Educación, la Ciencia y la Cultura.

Rimbau MuÑoz, Francesc Manuel

1988 El matrimonio en el "Itinerario para párrocos de Indios" de Alonso de la Peña Montenegro: aportación jurídico-pastoral a la introducción del matrimonio cristiano en las Indias durante los siglos XVI-XVII. Romae. Pontificium Athenaeum Sanctae Crucis, Facultas Iuris Canonici.

RituALE

1623 ---- Romanum Pauli V Pont. Max. iussu editum. Paris.

Roca SuÁRez-Inclán, Juan Manuel

1995 Los Sínodos de Quito en el siglo XVI: (aspectos jurídico-pastorales). Romae, Pontificium Athenaeum Sanctae Crucis, Facultas Iuris Canonici.

Saranyana, Josep-Ignasi - Alejos Grau, Carmen (et. al.)

1996 Historia de la teología latinoamericana. Vol. 1: Siglos XVI y XVII. Pamplona, Eunate.

SíNODO

1984 ---- de Concepción, Chile, 1744. Pedro Felipe de Azúa e Iturgoyen. Madrid, Salamanca, CSIC, Instituto de Historia de la Teología.

1970 ---- diocesanos de Santo Toribio, 1582-1604. Cuernavaca. CIDOC.

1983 ----- de Santiago de Chile de 1688 y 1763. Bernardo Carrasco Saavedra, Manuel de Alday y Aspee. Madrid - Salamanca. CSIC - Instituto de Historia de la Teología.

1996 ---- de Quito 1594 y Loja 1596. Madrid. Editorial Revista Agustiniana. 
ScHöCH, Nikolaus

1997 “La solennizzazione giuridica della 'forma canonica' nel decreto Tametsi del concilio di Trento". Antonianum. Roma, nº 72/4, pp. 639-672.

Soto Rábanos, José M. (ed.)

1987 Sínodos de Lima de 1613 y 1636. Bartolomé Lobo Guerrero, Fernando Arias de Ugarte. Madrid - Salamanca. CSIC - Instituto de Historia de la Teología.

TIneO, Primitivo

1990 Los concilios limenses en la evangelización latinoamericana. Pamplona. Eunsa.

USUNÁRIZ GARAYOA, Jesús M.

2004 "El matrimonio y su reforma en el mundo hispánico durante el Siglo de Oro: la promesa matrimonial". En Arellano - Godoy (eds.), Temas del barroco hispánico. Madrid - Frankfurt. Iberoamericana - Vervuert, pp. 293-312.

VARGas Ugarte, Rubén

1951 Concilios Limenses, 1551-1772. Vol. 1. Lima. Tipografía Peruana.

1959-62 Historia de la Iglesia en el Perú. Burgos. Aldecoa.

Velasco, Bartolomé

1964 "El Concilio Provincial de Charcas de 1629”. Missionalia Hispánica. Madrid, no 21/61, pp. 79-130.

Venegas, Miguel,

1731 Manual de párrocos para administrar los santos sacramentos y ejercer otras funciones eclesiásticas conforme al Ritual romano. Escrito por el padre Miguel Venegas de la sagrada Compañia de Jesús, quien lo dedica a los padres misioneros de la misma Compañia de Jesús de esta Provincia de Nueva España. Con licencia de los superiores. En México. por Joseph Bernardo de Hogal, ministro e impresor del Real y Apostólico Tribunal de la Santa Cruzada en toda esta Nueva España.

Veracruz, Alonso de la

2009 Speculum coniugiorum. Espejo de matrimonios: matrimonio y familia. Luciano BARP Fontana (ed.). México D.F. Universidad La Salle - Facultad de Filosofía y Letras Universidad Nacional Autónoma de México.

VILLEGAS, Juan

1975 Aplicación del concilio de Trento en Hispanoamérica 1564-1600. Provincia eclesiástica del Perú. Montevideo. Instituto Teológico del Uruguay.

Zaballa Beascoechea, Ana

2016 "Promises and Deceits: Marriage among Indias in New Spain in the Seventeenth and Eighteenth Centuries". The Americas: A Quarterly Review of Latin American History. Cambridge, no 73/1, pp. 59-82.

ZÁraTe, Miguel de

1734 Brevis forma administrandi apud indos sacramenta alia que ad sacrum rerum cultum... Ioannem de la Roca, Matriti, Tipographia Regia.

ZARRI, Gabriella

1996 "Il matrimonio tridentino". En Prodi - ReInHard (eds.), Il concilio di Trento e il moderno. Bologna. Il Mulino, pp. 437-483.

Zulaica Gárate, Román

1991 Los franciscanos y la imprenta en México en el siglo XVI. México. Universidad Nacional Autónoma, Instituto de Investigaciones Bibliográficas. 